\title{
Apoptosis-related protein-1 acts as a tumor suppressor in cholangiocarcinoma cells by inducing cell cycle arrest via downregulation of cyclin-dependent kinase subunits
}

\author{
JIANYONG ZHENG ${ }^{1,2 *}$, QINLONG LI ${ }^{2,3 *}$, WEIHUA WANG ${ }^{2,4 *}$, YINGMEI WANG $^{2,3}$, \\ XIN FU ${ }^{2,3}$, WENYONG WANG ${ }^{2,3}$, LINNI FAN ${ }^{2,3}$ and WEI YAN ${ }^{2,3}$ \\ ${ }^{1}$ Department of Gastrointestinal Surgery, ${ }^{2}$ State Key Laboratory of Cancer Biology, and ${ }^{3}$ Department of Pathology, \\ Xijing Hospital, Fourth Military Medical University; ${ }^{4}$ Department of Pharmacogenomics, School of Pharmacy, \\ Fourth Military Medical University, Xi'an, Shaanxi 710032, P.R. China
}

Received August 1, 2015; Accepted October 13, 2015

DOI: $10.3892 /$ or.2015.4422

\begin{abstract}
Cholangiocarcinoma, a malignancy arising from the biliary tract, is associated with high mortality due to the late diagnosis and lack of effective therapeutic approaches. Our knowledge of the molecular alterations during the carcinogenesis of cholangiocarcinoma is limited. Previous study suggests that apoptosis-related protein-1 (Apr-1) is involved in cancer cell proliferation and survival. In the present study, we first detected the expression pattern of Apr-1 in human cholangiocarcinoma tissues and the effects of forced Apr-1 expression on cell proliferation and cell cycle progression. Cell cycle gene array analysis was used to identify downstream molecules that were regulated by Apr-1, and their expression levels were further evaluated in human cholangiocarcinoma tissues. We showed that Apr-1 expression was downregulated in human cholangiocarcinoma tissues. Forced expression of Apr-1 inhibited cell proliferation of cholangiocarcinoma cell line QBC939 and induced G2/M phase arrest. Downregulation of cell cycle-related genes cyclin-dependent kinase $(C d k) 2$, and cyclin-dependent kinase subunits $(C k s) 1$ and 2 was involved in Apr-1-induced cell cycle arrest. Furthermore, we found that Cdk2 and Cks1/2 expression levels were elevated in human cholangiocarcinoma tissues. Taken together, our data showed that Apr-1 plays a crucial role in cell proliferation by controlling cell cycle progression, implying a tumor-suppressor function of Apr-1 in cholangiocarcinoma carcinogenesis. Thus, the present study provides a rationale to further study the underlying mechanisms of Apr-1 downregulation in
\end{abstract}

Correspondence to: Dr Wei Yan, Department of Pathology, Xijing Hospital, Fourth Military Medical University, 15 West Changle Road, Xi'an, Shaanxi 710032, P.R. China

E-mail:yan070@sina.com

*Contributed equally

Key words: Apr-1, cell cycle, Cdk2, Cks1,Cks2, cholangiocarcinoma cholangiocarcinoma for exploring potential diagnostic and therapeutic targets.

\section{Introduction}

Cholangiocarcinoma is defined as an epithelial tumor with features of cholangiocyte differentiation. According to the anatomic location, it is categorized as either intrahepatic or extrahepatic cholangiocarcinoma. Although cholangiocarcinoma accounts for $3 \%$ of all gastrointestinal tumors, it is the most common biliary malignancy and the second most common hepatic malignancy after hepatocellular carcinoma (1). The overall survival rate of cholangiocarcinoma of less than $5 \%$ at 5 years has not significantly changed over the past 3 decades (2). Surgical treatment is the preferred option for all subtypes. Yet, surgical intervention is limited due to the lack of effective markers for early diagnosis, thus only a small number of patients benefit from surgery. Furthermore, a high postoperative recurrence rate and low sensitivity to chemotherapeutics are critical factors which contribute to the poor prognosis of cholangiocarcinoma $(3,4)$. Several risk factors including primary sclerosing cholangitis, liver fluke infestation and hepatolithiasis have been described. However, little is known concerning the mechanisms of carcinogenesis. Therefore, there is a dire need for improving our understanding of the biology of cholangiocarcinoma to develop effective early diagnostic and therapeutic options.

Apoptosis-related protein-1 (Apr-1), also known as melanoma-associated antigen (MAGE)-H1 and restin, was first cloned by our group from the apoptotic tumor cell line HL-60 when induced by all-trans retinoic acid (ATRA) (5). It belongs to the MAGE gene superfamily based on the bioinformatic analysis of its gene structure compared with other homologues in the GenBank (6). According to their expression patterns, MAGE genes can be divided into two groups. Type I MAGE genes are expressed in tumors of various histological origins, but are completely silent in normal tissues, with the exception of male germ cells and placenta; thus, the corresponding proteins represent attractive targets for cancer immunotherapy (6). On the contrary, type II MAGE genes are ubiquitously expressed 
in somatic cells, both in tumors and normal adult tissues, which suggests that they may play an important role in biological processes (7). Although the activation and expression of MAGEs were reported in various human cancers including cholangiocarcinoma, the physiological function of MAGEs remains largely unknown $(8,9)$. However, the involvement of MAGEs in the regulation of cell cycle progression (10) and apoptosis $(11,12)$ has been suggested. Thus, the identification of the mechanisms responsible for the biological functions of MAGEs may shed new light on the understanding of the cause and development of cholangiocarcinoma.

According to our previous study, the expression pattern of Apr-1 indicates it is a type II MAGE gene and is involved in cancer cell proliferation and survival $(13,14)$. In the present study, we first examined the expression pattern of Apr-1 in human cholangiocarcinoma tissues, and then investigated the effects of induced overexpression of Apr-1 on cell growth and cell cycle regulation in human cholangiocarcinoma cell line QBC939. Furthermore, we analyzed the cell cycle-specific gene expression profile in QBC939 cells upon Apr-1 expression, as well as the expression of several key cell cycle regulatory proteins in human cholangiocarcinoma tissues. These studies facilitate a better understanding of the fundamental aspects of Apr-1, as a type II MAGE gene, in the tumorigenesis and tumor development of cholangiocarcinoma.

\section{Materials and methods}

Tissues. Four fresh-frozen cholangiocarcinoma samples and matched tumor-adjacent tissues obtained from Xijing Hospital (Fourth Military Medical University, Xi'an, Shaanxi Province, China) were collected and stored at $-70^{\circ} \mathrm{C}$. Formalin-fixed paraffin-embedded (FFPE) human cholangiocarcinoma tissue and tumor-adjacent tissue samples were collected from the Department of Pathology, Xijing Hospital. Ethical approval was obtained from the Xijing Hospital Ethics Committee.

Reagents. Anti-Apr-1 (anti-MAGE-H1) polyclonal antibody (HPA011324) was purchased from Sigma-Aldrich (St. Louis, MO, USA). Anti-Cdk2 (ab6538), anti-Cks1/2 (ab54643) and anti- $\beta$-actin (ab8227) rabbit polyclonal antibodies were purchased from Abcam (Shanghai,China). Restriction enzymes BamHI, XbaI, SalI, ScaI, ExTaq polymerase, DNA marker DL2000, $\lambda$ DNA/EcoRI+HindIII marker were purchased from Takara (Dalian, China). Liposome ${ }^{\mathrm{TM}}$ reagent, Dulbecco's modified Eagle's medium (DMEM) and fetal bovine serum (FBS) were obtained from Gibco-BRL (Gaithersburg, MD, USA). RNasin was purchased from Promega (Madison, WI, USA). G418 and TRIzol were from Invitrogen (Carlsbad, CA, USA). High-capacity cDNA reverse transcription kit was from Applied Biosystems (Carlsbad, CA, USA).

Plasmid. A BamHI site was introduced to the 5'-end and a SalI site was introduced to the 3 '-end of the primers for cloning the open reading frame of Apr-1. The sequences were as follows: sense BamHI, 5'-TAGGATCCggagacatgcetcggg-3'; antisense SalI, 5'-ACGCGTCGACgatctacttaaggggc-3'. The purified PCR products and pcDNA3.0 vector were cut by $\mathrm{BamHI} / \mathrm{Sal}$ and $B a m \mathrm{HI} / X h o I I$, respectively. The digested fragments were harvested and cloned into pcDNA3.0 between the same sites of SalI/XhoI to yield pcDNA3.0-Apr-1. The recombinant plasmid was confirmed by digestion of SalI/XhoI and sequencing.

Cell culture. Human cholangiocarcinoma QBC939 cells were stocked in our laboratory. Cells were cultured in DMEM containing $10 \%$ FBS, $50 \mathrm{IU} / \mathrm{ml}$ penicillin and $50 \mu \mathrm{g} / \mathrm{ml}$ gentamycin at $37^{\circ} \mathrm{C}$ under an atmosphere of $5 \% \mathrm{CO}_{2}$. For gene transfection, QBC939 cells in optimal growth conditions were divided into 3 groups: the control (QBC939 cells), blank vector group (pcDNA3.0-transfected QBC939 cells) and experimental group (pcDNA3.0-Apr-1-transfected QBC939 cells). Transfection procedures were performed according to the manufacturer's instructions. The resistant cells were screened by G418. G418-resistant clones were obtained after a 2-week selection.

Quantitative RT-PCR. Total RNA from the frozen tissues or QBC939 cells was extracted using TRIzol following the manufacturer's instructions. Reverse transcription reactions were conducted using a high-capacity cDNA reverse transcription kit. All primers were optimized for amplification under reaction conditions as follows: $95^{\circ} \mathrm{C}$ for $10 \mathrm{~min}$, followed by 30 cycles of $95^{\circ} \mathrm{C}$ for $15 \mathrm{sec}$ and $60^{\circ} \mathrm{C}$ for $1 \mathrm{~min}$. Melt curve analysis was performed for all samples after completion of the amplification protocol. $\beta$-actin was used as the housekeeping gene expression control. Listed below are the primer sequences used for quantitative PCR: Cdk2 forward, 5'-TCTGCCA TTCTCATCGGGTC-3' and Cdk2 reverse, 5'-ATTTGCAGC CCAGGAGGATTT-3'; Cks1 forward, 5'-AGCAAACCGAGC GATCATGT-3' and Cks1 reverse, 5'-TGCTGAACGCCAAG ATTCCT-3'; Cks2 forward, 5'-TCTTCGCGCTCTCGTTT CAT-3' and Cks2 reverse, 5'-TGGACACCAAGTCTCCT CCA-3'.

MTT cell proliferation assay. Each group of QBC939 cells was seeded at $1 \times 10^{4}$ cells/well into a 96-well plate. For cell growth analysis, $20 \mu 1$ freshly made MTT $(5 \mathrm{mg} / \mathrm{ml})$ was added into each well and incubated for $4 \mathrm{~h}$ at $37^{\circ} \mathrm{C}$. Then, cell culture media were removed and replaced with $150 \mu 1$ of dimethylsulfoxide (DMSO) for a further 10-min incubation with gentle shaking until the crystals were dissolved. The optical density (OD) value of each well was measured using a microculture plate reader (Coulter American) with a test wavelength of $490 \mathrm{~nm}$. Three duplicate wells for each group were measured per day.

Cell cycle analysis. The floating and adherent cells were harvested and washed twice with phosphate-buffered saline (PBS), then re-suspended in $300 \mu \mathrm{l}$ PBS and fixed by adding $700 \mu \mathrm{l}$ cold ethanol in $70 \%$ ethanol at $4^{\circ} \mathrm{C}$ overnight. After washing twice with PBS, $100 \mu 1$ of fixed cells $\left(\sim 1 \times 10^{6}\right.$ cells $)$ were stained with $300 \mu 1$ propidium iodide (PI) for $15 \mathrm{~min}$. Cell cycle analysis by flow cytometry was performed. The percentages of cells at the G1, G2 and S phases were measured.

Cell cycle gene expression array analysis. To determine the expression of cell cycle-specific genes, a GEArray Q series human cell cycle gene array kit (SuperArray Biosciences, Frederick, MD, USA) was used. Total RNA was isolated from 
A

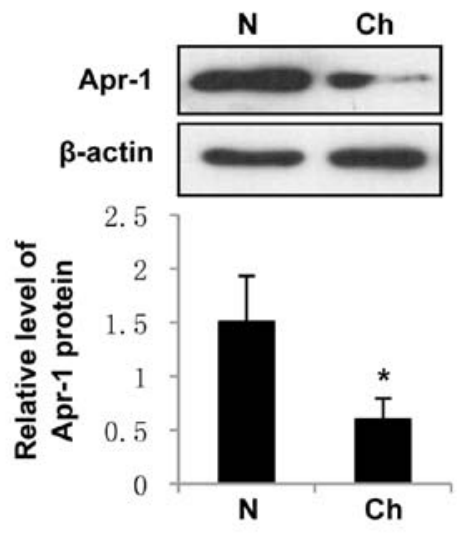

B

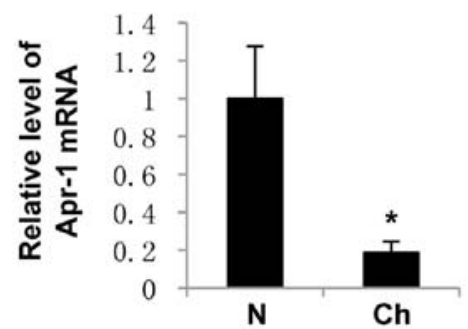

D Cholangiocarcinoma tissue
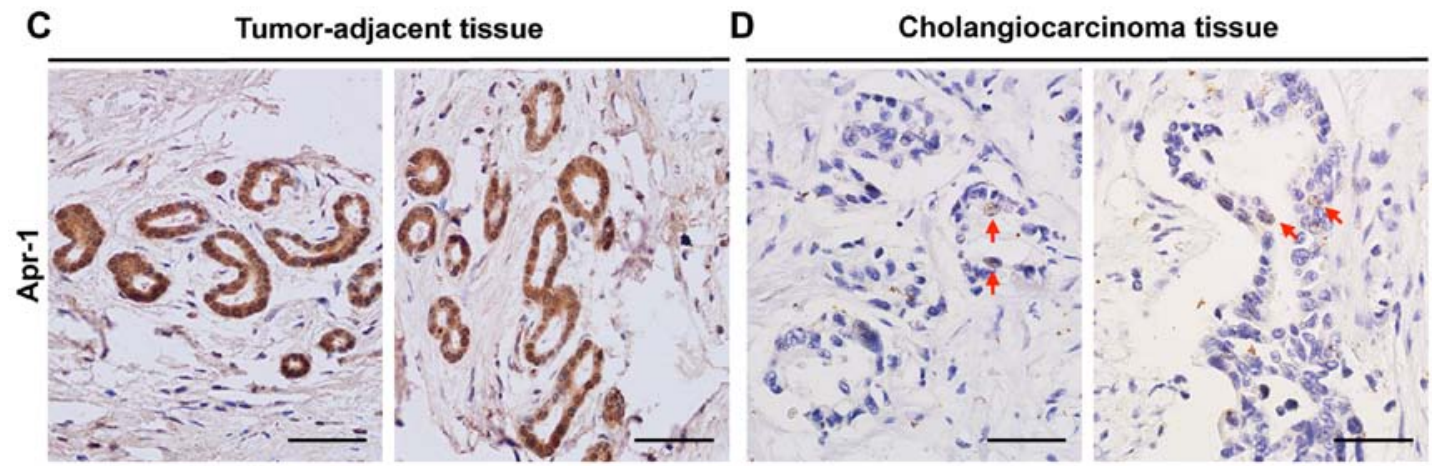

Figure 1. Expression of Apr-1 in human cholangiocarcinoma tissues. (A) Western blot assay was performed to analyze Apr-1 expression in human intrahepatic cholangiocarcinoma and paired tumor-adjacent hepatic tissues. The relative protein levels of Apr-1 were normalized to $\beta$-actin by gray value analysis. (B) qRT-PCR assay was used to assess Apr-1 transcription. N, normal tumor-adjacent hepatic tissues; Ch, cholangiocarcinoma tissues. Data represent mean \pm SEM. The statistical difference was determined by two-sided Student's t-test. ${ }^{*} \mathrm{p}<0.05$. (C and D) Immunohistochemical staining of Apr-1 in paraffinembedded human tissue samples. Arrows indicate Apr-1-positive cholangiocarcinoma cells. Scale bar, $50 \mu \mathrm{m}$.

QBC939 cells transfected for $48 \mathrm{~h}$ in $100-\mathrm{mm}$ dishes with $10.0 \mu \mathrm{g}$ of either empty vector pcDNA3.0 or pcDNA3.0-Apr-1. Both RNA samples were reverse-transcribed to produce ${ }^{32} \mathrm{P}$-labeled probes following the manufacturer's protocol. Cell cycle-specific genes in the nylon membranes were hybridized to heat denatured radiolabeled probes at $55^{\circ} \mathrm{C}$ for $16 \mathrm{~h}$ in a hybridization buffer provided by the manufacturer. After washing twice in $2 \mathrm{X} \mathrm{SSC} / 1 \% \mathrm{SDS}$, followed by two additional washes in $0.1 \mathrm{X} \mathrm{SSC} / 1 \% \mathrm{SDS}$ at $55^{\circ} \mathrm{C}$ for $15 \mathrm{~min}$ each, the membranes were exposed to X-ray film. The spots were detected by autoradiography, and the intensities of the corresponding spots in the two membranes were compared for two RNA populations used to generate the probes.

Western blotting. Immunoblot analysis was performed according to standard procedures using the following antibodies and dilutions: anti-Apr-1 1:500, anti-Cdk2 1:1,000, anti-Cks1/2 1:1,000 and anti- $\beta$-actin 1:1,000. Equal amounts of protein from the cells and tissues were separated by SDS-PAGE and transferred to polyvinylidene fluoride (PVDF) membranes (Bio-Rad, Shanghai, China). The membranes were blocked with milk, and primary antibody incubations were performed at room temperature for $2 \mathrm{~h}$. Secondary antibody HRP-conjugated anti-rabbit $(1: 5,000)$ was used and signals were detected with SuperSignal West Pico Substrate (Thermo Scientific, Shanghai, China). The visualization of bands was performed by exposure to high-performance autoradiography film.
Immunohistochemistry. Paraffin-embedded tissue sections on microscopic slides were processed through a graded series of alcohols and rehydrated in distilled water. Heat-induced antigen retrieval was performed by citrate buffer $(10 \mathrm{mmol} / \mathrm{l}$ concentration, $\mathrm{pH}$ 6.0), and standard indirect biotin-avidin immunohistochemical analysis was performed as previously described $(15,16)$.

Statistical analysis. The data are presented as mean \pm SEM. Statistical analysis was performed using SPSS 21.0. Statistical evaluation of the data was performed by two-way analysis of variance (ANOVA) or unpaired t-test (two groups). A value of $p<0.05$ was considered to indicate a statistically significant result.

\section{Results}

Apr-1 expression is reduced in human cholangiocarcinoma tissues. We performed western blotting and qRT-PCR assay to evaluate the Apr-1 expression in pooled samples of 4 human intrahepatic cholangiocarcinoma and paired tumor-adjacent hepatic tissues. The results showed that Apr-1 expression was significant lower in the cholangiocarcinoma tissues than that in the tumor-adjacent hepatic tissues (Fig. 1A and B). We next examined Apr-1 expression in 6 pathologically graded (moderate to well differentiated) human cholangiocarcinoma FFPE samples by immunohistochemistry (IHC). All normal or tumor-adjacent bile ducts exhibited medium to strong positive 


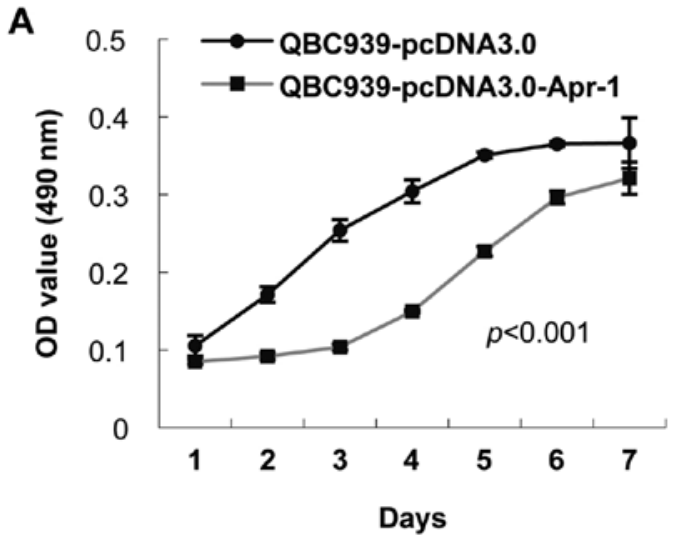

B

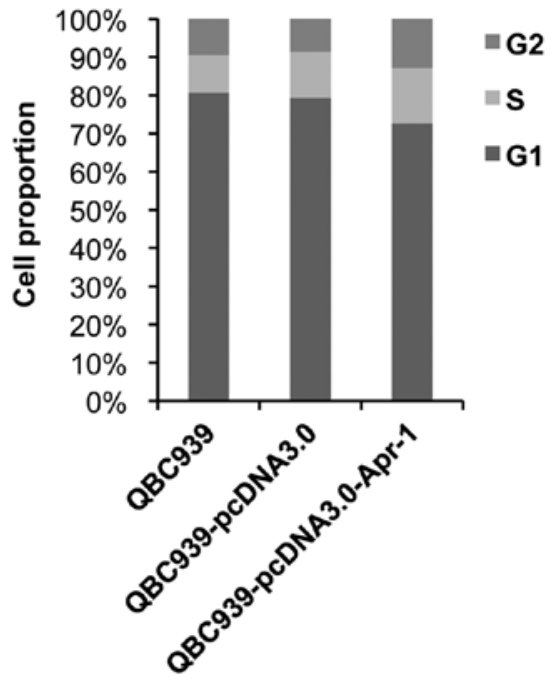

C
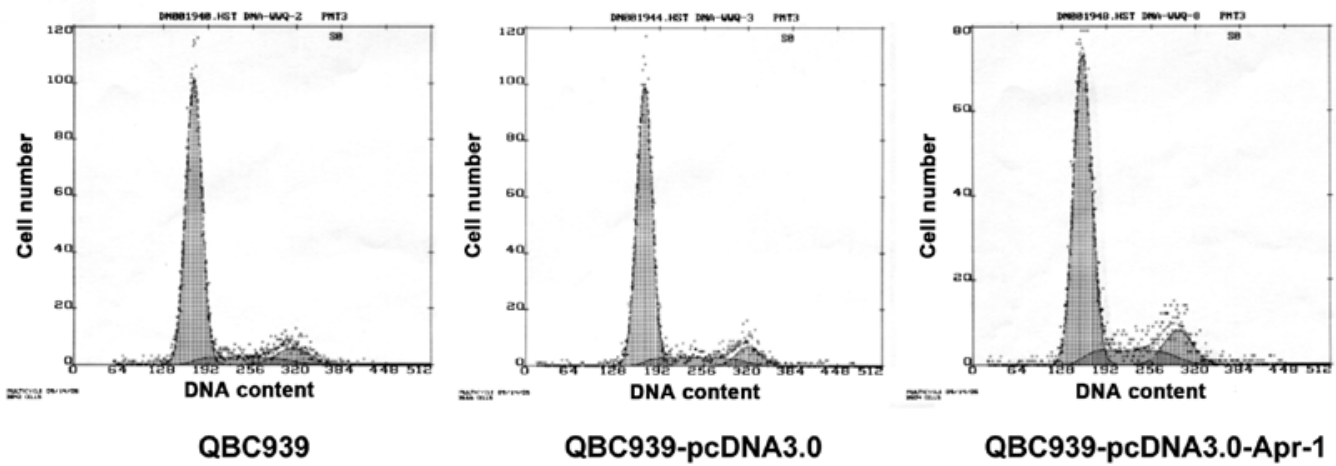

Figure 2. Effects of Apr-1 expression on the cell growth and cell cycle progression of QBC939 cells. (A) Growth curve of QBC939-pcDNA3.0 (transfected with pcDNA3.0) and QBC939-pcDNA3.0-Apr-1 (transfected with pcDNA3.0-Apr-1) cells by MTT cell proliferation assay. Data represent the mean \pm SEM. $\mathrm{p}<0.001$, as determined by two-way ANOVA. (B and C) Cell cycle analysis of QBC939 (G1, 80.7\%; G2, 9.5\%; S, 9.8\%), QBC939-pcDNA3.0 (G1, 79.4\%; G2, $8.6 \% ; \mathrm{S}, 12.0 \%)$ and QBC939-pcDNA3.0-Apr-1 cells (G1, 72.7\%; G2, $12.8 \%$;, $14.5 \%$ ) by flow cytometry.

staining of Apr-1 in both the cytoplasm and nuclei (Fig. 1C). In contrast, Apr-1 protein was undetectable in most of the cholangiocarcinoma tissues. Only rare carcinoma cells showed very weak trace nuclear expression of Apr-1 (Fig. 1D). We did not find any Apr-1 expression in the samples derived from human cholangiocarcinoma cell line QBC939 (data not shown). Therefore, it appears that Apr-1 expression is essential for normal cell function and is downregulated during cholangiocarcinoma development.

Apr-1 inhibits cell proliferation of QBC939 cells by inducing G2/M phase arrest. Given the fact that QBC939 cells do not express Apr-1, we sought to investigate the effects of induced overexpression of Apr-1 on cholangiocarcinoma cell proliferation and survival. QBC939 cells were transfected with pcDNA3.0-Apr-1, and stable cells were screened by G418. MTT assay was carried out to analyze the viability of the QBC939 cells with Apr-1 expression. The results showed that the growth of the QBC939-pcDNA3.0-Apr-1 cells was significantly inhibited ( $\mathrm{p}<0.001$, by two-way ANOVA) (Fig. 2A). Subsequently, we analyzed changes in the cell cycle distribution in the QBC939, QBC939-pcDNA3.0 and QBC939-pcDNA3.0-Apr-1 cells. The results demonstrated that QBC939-pcDNA3.0-Apr-1 cells were promoted to enter into the following phase from the G1 phase, which resulted in $4.2 \%$ more cells arrested in the
G2/M phase, coinciding with $2.5 \%$ more cells accumulated in the $\mathrm{S}$ phase when compared with the QBC939-pcDNA3.0 group (Fig. 2B). Meanwhile, cell death was not observed in these three cell lines. These data indicate that Apr-1 may play a role in cholangiocarcinoma cell proliferation by negatively regulating the cell cycle at the $\mathrm{G} 2 / \mathrm{M}$ point.

Cdk2, Cks1 and Cks2 are involved in Apr-1-induced cell cycle arrest. Based on the above data, we further investigated whether the transcription levels of cell cycle-regulatory genes are affected by expression of Apr-1. Cell cycle-specific gene expression array was used to determine the differences in gene expression between the QBC939-pcDNA3.0-Apr-1 and QBC939-pcDNA3.0 cells. The results showed that 23 cell cycle-specific genes including several cyclins and cyclindependent kinases $(C d k s)$ were downregulated $>2$-fold in the QBC939-pcDNA3.0-Apr-1 cells compared with the levels in the QBC939-pcDNA3.0 group (Fig. 3A and Table I). There were also two genes, $S$ phase kinase-associated protein 2 (Skp2) and ubiquitin-activating enzyme (UBE1) which are ubiquitin signaling pathway factors associated with the cell cycle, that were found to be upregulated upon Apr-1 expression (Table I). Notably, $C d k 1$ and $C d k 2$, cyclin-dependent kinase catalytic subunits that are important regulators of cell cycle transition between different cell cycle stages, were downregulated $>4$-fold 
A

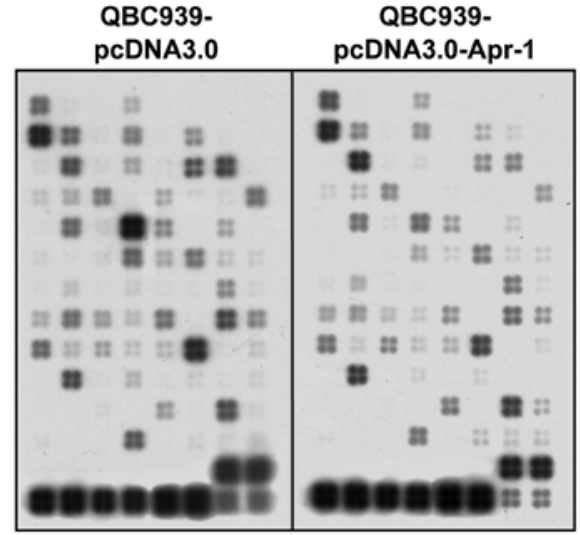

B

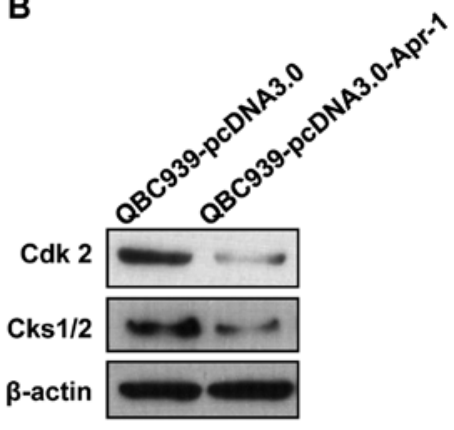

C
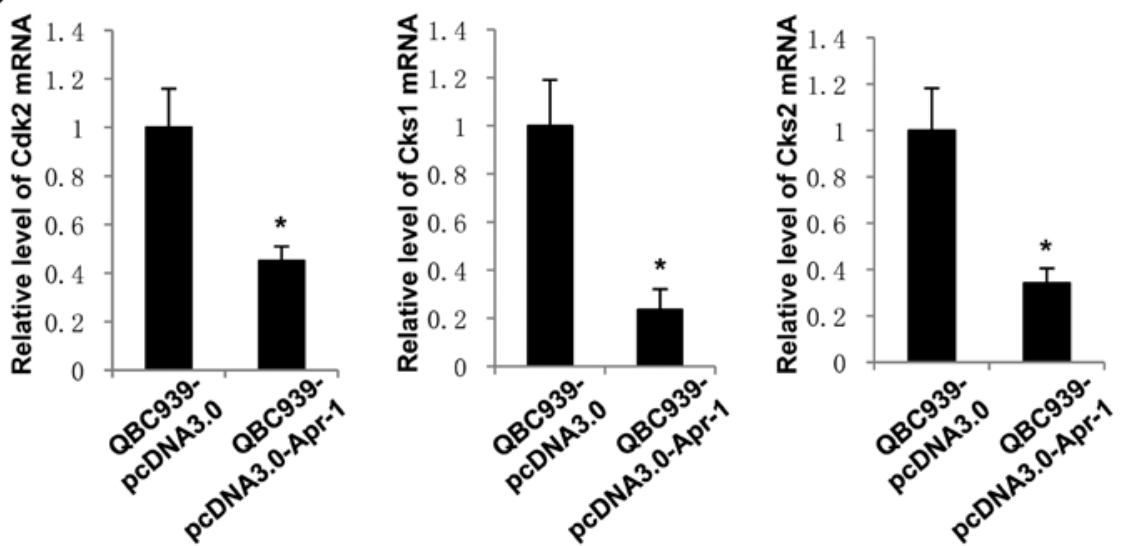

Figure 3. Apr-1 expression in QBC939 cells regulates transcription of cell cycle-related genes Cdk2, Cks1 and Cks2. (A) Specific-cell cycle cDNA microarray analysis showed a discrepancy in gene expression pattern between QBC939-pcDNA3.0 and QBC939-pcDNA3.0-Apr-1 cells. (B) Western blot assay for Cdk2 and Cks1/2 expression in QBC939-pcDNA3.0 and QBC939-pcDNA3.0-Apr-1 cells. (C) Relative levels of Cdk2, Cks1 and Cks2 transcripts in the QBC939-pcDNA3.0 and QBC939-pcDNA3.0-Apr-1 cells as measured by qRT-PCR $24 \mathrm{~h}$ after transfection. Data represent the mean \pm SEM. The statistical difference was determined by two-sided Student's t-test. "p $<0.05$.

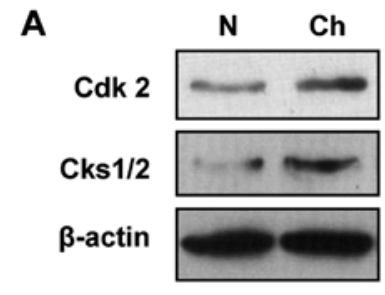

B
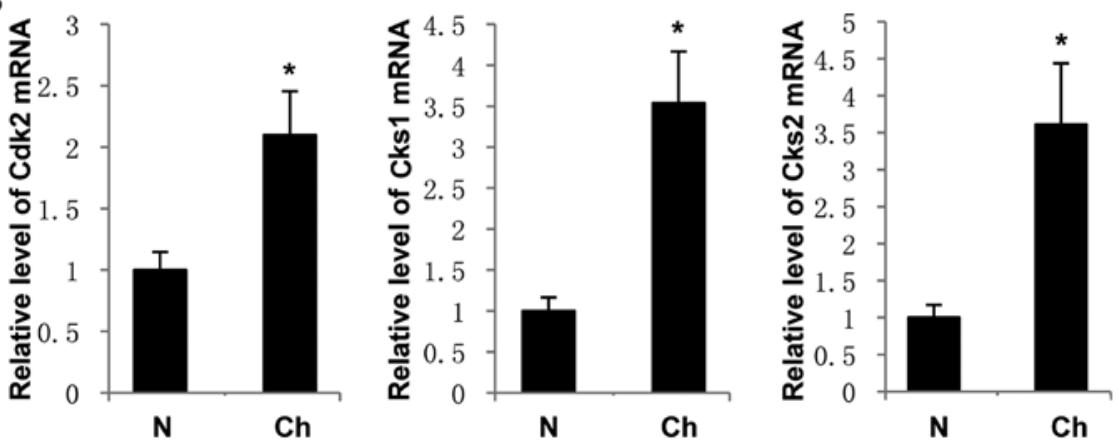

Figure 4. Expression of cell cycle-related proteins Cdk2 and Cks1/2 in human cholangiocarcinoma tissues. (A) Western blotting assay for Cdk2 and Cks1/2 expression in human cholangiocarcinoma tissues. (B) Relative levels of Cdk2, Cks1 and Cks2 transcripts in normal tumor-adjacent hepatic (N) and cholangiocarcinoma tissues $(\mathrm{Ch})$ as measured by qRT-PCR. Data represent the mean \pm SEM. The statistical difference was determined by two-sided Student's $\mathrm{t}$-test. " $\mathrm{p}<0.05$.

by Apr-1. Moreover, the expression levels of Cdk-interacting protein $C k s 1$ and cyclin-dependent kinase subunit $(C k s 2)$, which are tightly associated with Cdks and mitotic entry, were decreased 3-fold upon Apr-1 expression in the QBC939 cells. 
Table I. Apr-1 regulates transcription of cell cycle-related genes in QBC939 cells (downregulated or upregulated >2-fold).

\begin{tabular}{|c|c|c|c|}
\hline Gene name & Description & Fold-change & GenBank \\
\hline Cks1 & Cyclin-dependent kinase subunit 1 & -2.934 & NM_001826 \\
\hline Cks2 & Cyclin-dependent kinase subunit 2 & -3.126 & NM_001827 \\
\hline $\mathrm{Cdk} 2$ & Cyclin-dependent kinase 2 & -4.477 & NM_001798 \\
\hline Cdk1 & Cell division cycle $2, \mathrm{G} 1$ to $\mathrm{S}$ and $\mathrm{G} 2$ to $\mathrm{M}$ & -4.648 & NM_001786 \\
\hline Cyclin $\mathrm{H}$ & Cyclin $\mathrm{H}$ & -2.139 & NM_001239 \\
\hline MRE11A & Homolog A (Cerevisiae) & -3.049 & NM_005590 \\
\hline CDK8 & Cyclin-dependent kinase 8 & -3.258 & NM_001260 \\
\hline CDC45 & CDC45 cell division cycle 45 -like & -3.298 & NM_003504 \\
\hline P21/Waf1 & Cyclin-dependent kinase inhibitor $1 \mathrm{~A}$ & -3.632 & NM_000389 \\
\hline p16/INK4 & Cyclin-dependent kinase inhibitor 2A & -3.782 & NM_000077 \\
\hline CHK2/RAD53 & CHK2 checkpoint homolog & -3.872 & NM_007194 \\
\hline Chk1 & CHK1 checkpoint homolog & -3.936 & NM_001274 \\
\hline PRC1 & Protein regulator of cytokinesis 1 & -4.022 & NM_003981 \\
\hline $\mathrm{E} 2 \mathrm{~F}$ & E2F transcription factor 1 & -4.061 & NM_005225 \\
\hline P55CDC & CDC20 cell division cycle 20 homolog & -4.224 & NM_001255 \\
\hline Cyclin F & Cyclin F & -4.353 & NM_001761 \\
\hline $\mathrm{Cdk} 4$ & Cyclin-dependent kinase 4 & -4.441 & NM_000075 \\
\hline Cdc16 & CDC 16 cell division cycle 16 & -4.445 & NM_003903 \\
\hline GADD45 & Cell division cycle $2, \mathrm{G} 1$ to $\mathrm{S}$ & -4.612 & NM_001924 \\
\hline SUMO-1 & Ubiquitin-like 1 (sentrin) & -4.848 & NM_003352 \\
\hline Apaf-1 & Apoptotic protease activating factor & -4.925 & NM_001160 \\
\hline Cyclin D3 & Cyclin D3 & -4.942 & NM_001760 \\
\hline p18/INK4C & p18, inhibits CDK4 & -4.989 & NM_078626 \\
\hline Skp2 & $\mathrm{S}$ phase kinase-associated protein 2 & +2.427 & NM_005983 \\
\hline UBE1 & Ubiquitin-activating enzyme E1 & +2.012 & NM_003334 \\
\hline
\end{tabular}

Apr-1, apoptosis related protein-1.

To confirm the negative-regulatory effects of Apr-1 on Cdk2, Cks1 and Cks2 expression, we used western blotting and qRT-PCR assay to identify the changes in expression of these genes in the pcDNA3.0-Apr-1-transfected QBC939 cells. As shown in Fig. 3B and C, pcDNA3.0-Apr-1 transfection inhibited the expression of Cdk2 and Cks1/2 in the QBC939 cells at both the protein and mRNA levels. The results indicated that expression of Apr-1 induces G2/M phase arrest of cholangiocarcinoma cells potentially by inhibiting the transcription of Cdk2, Cks1 and Cks2.

Cdk2, Cks1 and Cks2 expression levels are elevated in human cholangiocarcinoma tissues. To further characterize the correlation between Apr-1 and Cdk2, Cks1 and Cks2 expression in cholangiocarcinoma, we detected Cdk2, Cks1 and $\mathrm{Cks} 2$ protein and mRNA levels in tumor and tumor-adjacent hepatic tissues. Western blotting showed that Cdk2 and Cks1/2 were accumulated in the samples of cholangiocarcinoma tissues compared with matched tumor-adjacent hepatic tissues (Fig. 4A), which was consistent with the results of qRT-PCR that Cdk2, Cks1 and Cks2 levels were significantly higher in cholangiocarcinoma tissues than that in tumoradjacent hepatic tissues (Fig. 4B). These data suggest that Apr-1 expression, which is reduced in cholangiocarcinoma, is negatively correlated with Cdk2, Cks1 and Cks2 expression.

\section{Discussion}

Cholangiocarcinoma is a highly malignant cancer with a poor prognosis. Abnormalities in various signaling cascades, molecules and genetic mutations are involved in the pathogenesis of cholangiocarcinoma. Recurrent mutations including KRAS, BRAF, TP53, Smad and p16 (INK4a) are characteristic of cholangiocarcinoma. KRAS and $B R A F$ mutant cholangiocarcinomas have been associated with a worse long-term survival. Meanwhile, disruption of the RAF/MEK/MAPK pathway by RAS or BRAF mutation has been found in $>60 \%$ of cholangiocarcinomas, indicating that these pathways are important in cholangiocarcinoma carcinogenesis (17). Wnt signaling also plays an important role in cholangiocarcinoma carcinogenesis through activation of downstream target genes such as cyclin D1 and c-myc $(18,19)$. Although extensive efforts have been made to explore the transformation mechanism of cholangiocarcinoma in the past decades, detailed molecular and cellular mechanisms remain unclear. More comprehensive understanding of the mechanisms involved in the pathogenesis of cholangiocarcinoma is critical for the development of effective therapies.

Apr-1 belongs to the MAGE superfamily for which over 30 members have been identified. Although the first MAGE family gene was discovered in 1991, MAGEs have been well 
studied for $>20$ years in melanomas (20), yet their functions still remain unclear.

Based on our previous study, Apr-1 protein was found to be localized in the nucleus and is believed to be an apoptosis-related gene since its transcripts were upregulated during all-trans-retinoic acid-induced apoptosis in human promyelocytic leukaemia cells $(5,14)$. In situ hybridization assay on tissue microarrays showed that Apr-1 is expressed in esophageal carcinoma, normal hepatic tissue and hepatic tissue adjacent to hepatocellular carcinoma, but is absent in normal esophageal mucosa and hepatocellular carcinoma (data not shown). The expression pattern suggests that Apr-1 is a type II MAGE gene. Recently, type II MAGE proteins are under increasing attention due to their roles in the regulation of cell cycle progression and apoptosis.

In the present study, we found that Apr-1 triggered cell cycle arrest in QBC939 cells. QBC939-pcDNA3.0-Apr-1 cells showed a decrease in the G1 phase and were dominantly arrested in the $\mathrm{G} 2 / \mathrm{M}$ phase after Apr-1 overexpression. Using gene expression array, we identified that Apr-1 induced G2/M phase arrest of QBC939 cells via a mechanism mediated by downregulation of the cell cycle checkpoint-related genes, in which Cdk2, Cks1 and Cks2 expression levels played critical roles during this course.

Cdks are a family of protein kinases that drive the cell cycle progression through their periodic activation. Cyclin-Cdk complexes phosphorylate specific substrates in a particular cell cycle phase (21). The cyclin B-Cdk1 complex is vital for entering mitosis ( $\mathrm{M}$ phase), while $\mathrm{Cdk} 2$ is involved with cyclin $A$ and $E$ and activated from late G1 until the onset of mitosis (22). Moreover, deregulation of $\mathrm{Cdk} 2$ can result in DNA damage accumulation and loss of DNA damage checkpoint control (23-25). In the present study, we found that Cdk1 and Cdk2 were inhibited by Apr-1 expression. Thus suggests that Apr-1 induces cholangiocarcinoma cell cycle arrest in the $\mathrm{G} 2$ phase by impairing the expression of Cdk1 and Cdk2.

Given their essential role in cell cycle progression, Cdk1 and $\mathrm{Cdk} 2$ are highly regulated by, among others, cyclin dependent-kinase subunit Cks1 and Cks2. The human cyclin kinase subunit family consists of two well-conserved members, Cks1 and Cks2, both of which were identified based on the sequence homology to yeast suc1 and Cks1 (also named Cdc28 kinase subunit 1) that are essential for cell cycle control (26). Accumulative evidence shows that the two Cks members have distinct regulatory functions in mammalian cells although $81 \%$ of protein products are identical and share one or more redundant functions in both humans and mice (27). Cks1 can specifically regulate cell cycle G1/S transition by promoting the process of $\mathrm{SCF}^{\mathrm{Skp} 2}$-mediated ubiquitination and p27 ${ }^{\mathrm{kip} 1}$ (a Cdk2 inhibitor) degradation $(28,29)$. Therefore, cells lacking Cks1 have elevated p27 and reduced Cdk2 activity $(29,30)$. Cks2 has been shown to be essential for the first metaphase/anaphase transition in mammalian meiosis; however, its function is not clearly identified in the cell cycle $(23,24,31,32)$. Recent study has shown that overexpression of $\mathrm{Cks} 1$ or $\mathrm{Cks} 2$ can maintain Cdk2 in an active state (33). Therefore, in the present study, decreased Cdk2 level upon Apr-1 expression could directly result from Apr-1 regulation and/or be mediated by Cks1 and Cks2 inhibition.
Numerous studies report abnormal Cks1/2 expression in various malignant tumors including hepatocellular carcinoma, bladder, gastric and breast cancer, and meningioma (34-38). However, the mechanistic link between Cks protein deregulation and oncogenesis remains to be elucidated. Liberal et al found that human mammary epithelial cells with Cks1 or Cks2 overexpression became resistant to DNA damage response mediated by cell cycle checkpoint that was triggered by oncoproteins, thus, allowing cells to continue proliferating even under replicative stress (33). More recently, Cks2 was found to be significantly elevated in cholangiocarcinoma tissues and its downregulation inhibited cholangiocarcinoma cell proliferation in vitro and in vivo; particularly, $\mathrm{Cks} 2 \mathrm{knockdown}$ induced cholangiocarcinoma cell cycle arrest in the G2/M phase by facilitating cell apoptosis, which suggests that $\mathrm{Cks} 2$ may serve as an independent prognostic factor in patients with cholangiocarcinoma (39). Consistently, we found that Cks1 and Cks2 were accumulated in human cholangiocarcinoma samples. Most importantly, we demonstrated that Apr-1 expression was downregulated in cholangiocarcinoma and induced overexpression of Apr-1 in cholangiocarcinoma cells inhibited cell proliferation, mechanistically mediated by $\mathrm{Cks} 1$ and $\mathrm{Cks} 2$ deficiency, indicating that Apr-1 can regulate the expression of Cks1 and Cks2 in cholangiocarcinoma. Two cell cycle-related genes, $S k p 2$ and $U B E 1$, showed $>2$-fold increase at the transcription level after overexpression of Apr-1. Skp2 is a member of the F-box family of substrate-recognition subunits of SCF ubiquitin-protein ligase complexes that has been implicated in ubiquitin-mediated degradation (40); UBE1, also known as an E1 enzyme, catalyzes the first step in the ubiquitination reaction (41). Both Skp2 and UBE1 function to regulate other cell cycle molecules by ubiquitination. It has been recognized that Skp2 can interact with Cks1 to degrade p2 $7^{\text {Kipl }}$ protein, which serves as a negative cell cycle regulator exemplifying a class of tumor suppressors that controls cell cycle progression (42). Recent findings indicate that high expression of Skp2 is associated with aggressiveness and a poor prognosis in a large variety of cancers, including cholangiocarcinoma (43). The present study did not address whether there is a feedback loop leading to upregulation of Skp2 upon Apr-1-induced cell cycle arrest. Additional studies are required to clarify the regulatory mechanisms involved in elevated $S k p 2$ and $U B E 1$ transcription induced by Apr-1 overexpression.

In conclusion, our data strongly suggest that Apr-1 has a tumor-suppressor function in cholangiocarcinoma cells, mechanistically by inducing cell cycle arrest through regulating a series of cell cycle regulators. Thus, our study lays a foundation for further investigation of the underlying mechanisms of Apr-1 downregulation during the development and progression of cholangiocarcinoma in order to explore potential therapeutic targets for cholangiocarcinoma treatment.

\section{Acknowledgements}

The present study was supported by the National Nature Science Foundation of China (no. 81472299).

\section{References}

1. Olnes MJ and Erlich R: A review and update on cholangiocarcinoma. Oncology 66: 167-179, 2004. 
2. Sandhu DS, Shire AM and Roberts LR: Epigenetic DNA hypermethylation in cholangiocarcinoma: Potential roles in pathogenesis, diagnosis and identification of treatment targets. Liver Int 28: 12-27, 2008.

3. Razumilava N and Gores GJ: Cholangiocarcinoma. Lancet 383: $2168-2179,2014$

4. Rizvi S and Gores GJ: Pathogenesis, diagnosis, and management of cholangiocarcinoma. Gastroenterology 145: 1215-1229, 2013.

5. Zhu F, Yan W, Zhao ZL, Chai YB, Lu F, Wang Q, Peng WD, Yang AG and Wang CJ: Improved PCR-based subtractive hybridization strategy for cloning differentially expressed genes. Biotechniques 29: 310-313, 2000.

6. Chomez P, De Backer O, Bertrand M, De Plaen E, Boon T and Lucas S: An overview of the MAGE gene family with the identification of all human members of the family. Cancer Res 61: 5544-5551, 2001.

7. Barker PA and Salehi A: The MAGE proteins: Emerging roles in cell cycle progression, apoptosis, and neurogenetic disease. J Neurosci Res 67: 705-712, 2002.

8. Bertrand M, Huijbers I, Chomez P and De Backer O: Comparative expression analysis of the MAGED genes during embryogenesis and brain development. Dev Dyn 230: 325-334, 2004.

9. Sang M, Wang L, Ding C, Zhou X, Wang B, Wang L, Lian Y and Shan B: Melanoma-associated antigen genes - an update. Cancer Lett 302: 85-90, 2011.

10. Saburi S, Nadano D, Akama TO, Hirama K, Yamanouchi K, Naito K, Tojo H, Tachi $\mathrm{C}$ and Fukuda MN: The trophinin gene encodes a novel group of MAGE proteins, magphinins, and regulates cell proliferation during gametogenesis in the mouse. J Biol Chem 276: 49378-49389, 2001.

11. Salehi AH, Roux PP, Kubu CJ, Zeindler C, Bhakar A, Tannis LL, Verdi JM and Barker PA: NRAGE, a novel MAGE protein, interacts with the p75 neurotrophin receptor and facilitates nerve growth factor-dependent apoptosis. Neuron 27: 279-288, 2000.

12. Selimovic D, Sprenger A, Hannig M, Haïkel Y and Hassan M Apoptosis related protein-1 triggers melanoma cell death via interaction with the juxtamembrane region of $\mathrm{p} 75$ neurotrophin receptor. J Cell Mol Med 16: 349-361, 2012.

13. Yan W, Li Q and Zhu F: Apoptosis-related genes cloned by improved subtractive hybridization. Zhonghua Zhong Liu Za Zhi 23: 193-195, 2001 (In Chinese).

14. Yan W, Wang W-L, Zhu F, Cheng SQ, Li QL, Wang L and Wang CJ: Cloning and subcellular localization of apr-1 - a new gene of tumor specific antigen family. Ai Zheng 24: 129-134, 2005 (In Chinese)

15. Zhang Y, Li Q, Zhu F, Cui J, Li K, Li Q, Wang R, Wang W, Wang W and Yan W: Subcellular localization of APMCF1 and its biological significance of expression pattern in normal and malignant human tissues. J Exp Clin Cancer Res 28: 111, 2009.

16. Zhang Y, Li Q, Huang W, Zhang J, Han Z, Wei H, Cui J, Wang Y and Yan W: Increased expression of apoptosis-related protein 3 is highly associated with tumorigenesis and progression of cervical squamous cell carcinoma. Hum Pathol 44: 388-393, 2013.

17. Robertson S, Hyder O, Dodson R, Nayar SK, Poling J, Beierl K, Eshleman JR, Lin MT, Pawlik TM and Anders RA: The frequency of $K R A S$ and $B R A F$ mutations in intrahepatic cholangiocarcinomas and their correlation with clinical outcome. Hum Pathol 44: 2768-2773, 2013.

18. Yothaisong S, Dokduang H, Techasen A, Namwat N, Yongvanit $P$, Bhudhisawasdi V, Puapairoj A, Riggins GJ and Loilome W: Increased activation of PI3K/AKT signaling pathway is associated with cholangiocarcinoma metastasis and PI3K/mTOR inhibition presents a possible therapeutic strategy. Tumour Biol 34: 3637-3648, 2013.

19. Maemura K, Natsugoe S and Takao S: Molecular mechanism of cholangiocarcinoma carcinogenesis. J Hepatobiliary Pancreat Sci 21: 754-760, 2014.

20. van der Bruggen $P$, Traversari $C$, Chomez $P$, Lurquin $C$, De Plaen E, Van den Eynde B, Knuth A and Boon T: A gene encoding an antigen recognized by cytolytic $\mathrm{T}$ lymphocytes on a human melanoma. Science 254: 1643-1647, 1991

21. Morgan DO: Cyclin-dependent kinases: Engines, clocks, and microprocessors. Annu Rev Cell Dev Biol 13: 261-291, 1997.

22. Pagano M, Pepperkok R, Lukas J, Baldin V, Ansorge W, Bartek J and Draetta G: Regulation of the cell cycle by the cdk 2 protein kinase in cultured human fibroblasts. J Cell Biol 121: 101-111, 1993.

23. Merrick KA, Larochelle S, Zhang C, Allen JJ, Shokat KM and Fisher RP: Distinct activation pathways confer cyclin-binding specificity on Cdk1 and Cdk2 in human cells. Mol Cell 32: 662-672, 2008
24. Tane $\mathrm{S}$ and Chibazakura T: Cyclin A overexpression induces chromosomal double-strand breaks in mammalian cells. Cell Cycle 8: 3900-3903, 2009.

25. Wheeler LW, Lents NH and Baldassare JJ: Cyclin A-CDK activity during G1 phase impairs MCM chromatin loading and inhibits DNA synthesis in mammalian cells. Cell Cycle 7: 2179-2188, 2008

26. Hayles J, Beach D, Durkacz B and Nurse P: The fission yeast cell cycle control gene cdc2: Isolation of a sequence sucl that suppresses cdc2 mutant function. Mol Gen Genet 202: 291-293, 1986.

27. Richardson HE, Stueland CS, Thomas J, Russell P and Reed SI: Human cDNAs encoding homologs of the small p34 ${ }^{\text {Cdc28 }}$

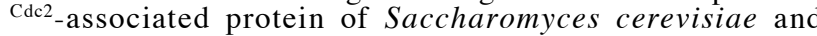
Schizosaccharomyces pombe. Genes Dev 4: 1332-1344, 1990.

28. Ganoth D, Bornstein G, Ko TK, Larsen B, Tyers M, Pagano M and Hershko A: The cell-cycle regulatory protein Cks1 is required for SCFSkp2-mediated ubiquitinylation of p27. Nat Cell Biol 3: 321-324, 2001.

29. Spruck C, Strohmaier H, Watson M, Smith AP, Ryan A, Krek TW and Reed SI: A CDK-independent function of mammalian Cks1: Targeting of SCF ${ }^{\mathrm{Skp} 2}$ to the CDK inhibitor p27 ${ }^{\mathrm{Kip} 1}$. Mol Cell 7: 639-650, 2001

30. Frontini M, Kukalev A, Leo E, Ng YM, Cervantes M, Cheng CW, Holic R, Dormann D, Tse E, Pommier Y, et al: The CDK subunit CKS2 counteracts CKS1 to control cyclin A/CDK2 activity in maintaining replicative fidelity and neurodevelopment. Dev Cell 23: 356-370, 2012.

31. Spruck CH, de Miguel MP, Smith APL, Ryan A, Stein P, Schultz RM, Lincoln AJ, Donovan PJ and Reed SI: Requirement of Cks2 for the first metaphase/anaphase transition of mammalian meiosis. Science 300: 647-650, 2003.

32. Rother K, Dengl M, Lorenz J, Tschöp K, Kirschner R, Mössner J and Engeland $\mathrm{K}$ : Gene expression of cyclin-dependent kinase subunit Cks 2 is repressed by the tumor suppressor $\mathrm{p} 53$ but not by the related proteins p63 or p73. FEBS Lett 581: 1166-1172, 2007.

33. Liberal V, Martinsson-Ahlzén HS, Liberal J, Spruck CH, Widschwendter M, McGowan CH and Reed SI: Cyclin-dependent kinase subunit (Cks) 1 or Cks2 overexpression overrides the DNA damage response barrier triggered by activated oncoproteins. Proc Natl Acad Sci USA 109: 2754-2759, 2012.

34. Shen DY, Fang ZX, You P, Liu PG, Wang F, Huang CL, Yao XB, Chen ZX and Zhang ZY: Clinical significance and expression of cyclin kinase subunits 1 and 2 in hepatocellular carcinoma. Liver Int 30: 119-125, 2010.

35. Chen R, Feng $\mathrm{C}$ and $\mathrm{Xu} \mathrm{Y}$ : Cyclin-dependent kinase-associated protein Cks2 is associated with bladder cancer progression. J Int Med Res 39: 533-540, 2011.

36. Kang MA, Kim J-T, Kim JH, Kim SY, Kim YH, Yeom YI, Lee Y and Lee HG: Upregulation of the cycline kinase subunit CKS2 increases cell proliferation rate in gastric cancer. J Cancer Res Clin Oncol 135: 761-769, 2009.

37. Tanaka F, Matsuzaki S, Mimori K, Kita Y, Inoue H and Mori M: Clinicopathological and biological significance of $C D C 28$ protein kinase regulatory subunit 2 overexpression in human gastric cancer. Int J Oncol 39: 361-372, 2011.

38. Menghi F, Orzan FN, Eoli M, Farinotti M, Maderna E, Pisati F, Bianchessi D, Valletta L, Lodrini S, Galli G, et al: DNA microarray analysis identifies $C K S 2$ and $L E P R$ as potential markers of meningioma recurrence. Oncologist 16: 1440-1450, 2011.

39. Shen DY, Zhan YH, Wang QM, Rui G and Zhang ZM: Oncogenic potential of cyclin kinase subunit-2 in cholangiocarcinoma. Liver Int 33: 137-148, 2013.

40. Cardozo T and Pagano M: The SCF ubiquitin ligase: Insights into a molecular machine. Nat Rev Mol Cell Biol 5: 739-751, 2004.

41. Weissman AM: Themes and variations on ubiquitylation. Nat Rev Mol Cell Biol 2: 169-178, 2001.

42. Frescas D and Pagano M: Deregulated proteolysis by the F-box proteins SKP2 and beta-TrCP: Tipping the scales of cancer. Nat Rev Cancer 8: 438-449, 2008.

43. Hashimoto N, Yachida S, Okano K, Wakabayashi H, Imaida K, Kurokohchi K, Masaki T, Kinoshita H, Tominaga M, Ajiki T, et al: Immunohistochemically detected expression of $\mathrm{p} 27^{\mathrm{Kipl}}$ and Skp2 predicts survival in patients with intrahepatic cholangiocarcinomas. Ann Surg Oncol 16: 395-403, 2009. 